NOTA

\title{
MESA DE TENSÃO COM AREIA: PROCEDIMENTOS PARA MONTAGEM E VALIDAÇÃO ${ }^{(1)}$
}

\author{
Herdjania Veras de Lima ${ }^{(2)} \&$ Álvaro Pires da Silva ${ }^{(3)}$
}

\begin{abstract}
RESUMO
Este trabalho apresenta um método prático e fácil para construção de uma mesa de tensão com camadas de areia constituídas de quartzo moído, para ser utilizada na determinação da retenção de água no solo até $100 \mathrm{hPa}$. A avaliação da mesa de tensão construída por esse método foi feita com amostras de solo indeformadas, com conteúdo de argila variando de 105 a $316 \mathrm{~g} \mathrm{~kg}^{-1} \mathrm{e}$ C orgânico de 19,8 a 39,0 $\mathrm{g} \mathrm{kg}^{-1}$. Utilizou-se um minitensiômetro e câmara de pressão de Richard para testar a eficiência da mesa de areia na aplicação da tensão nas amostras. Os resultados mostraram que os dados obtidos na mesa de areia foram confiáveis para determinação da curva de retenção de água no solo até $100 \mathrm{hPa}$, independentemente do conteúdo de argila e dos teores de matéria orgânica.
\end{abstract}

Termos de indexação: retenção de água no solo, método de laboratório.

\section{SUMMARY: SAND TENSION TABLE: PROCEDURES FOR CONSTRUCTION AND VALIDATION}

This paper presents and tests a practical and easy method for setting up a tension table using sand layers obtained as quartz powder in the determination of the soil moisture retention curve up to $100 \mathrm{hPa}$. Twenty-eight undisturbed cores with varying clay (105 to $316 \mathrm{~g} \mathrm{~kg}^{-1}$ ) and organic matter contents (1.98 to $3.90 \mathrm{dag} \mathrm{kg}^{-1}$ ) along with a mini tensiometer were used to test the sand table efficiency. The results showed that the sand tension table was very reliable when measuring soil water retention curve up to $100 \mathrm{hPa}$, regardless of the clay and organic matter contents.

Index terms: soil water retention, laboratory method.

(1) Recebido para publicação em setembro de 2006 e aprovado em junho de 2008.

(2) Professora do Instituto de Ciências Agrárias da Universidade Federal Rural da Amazônia. Av. Pres. Tancredo Neves 2501, Caixa Postal 917, CEP 66077-530 Belém (PA). E-mail: herdjania.lima@ufra.edu.br

(3) Professor do Departamento de Ciência do Solo, Escola Superior de Agricultura "Luiz de Queiroz" - ESALQ/USP. Caixa Postal 09, Av. Pádua Dias 11, CEP 13418-900 Piracicaba (SP). E-mail: apisilva@esalq.usp.br 


\section{INTRODUÇÃO}

A freqüente necessidade de drenagem da água em amostras de solo-normalmente a uma tensão próxima à capacidade de campo - tem induzido diversos pesquisadores à utilização de mesas de tensão. A determinação da retenção de água em baixas tensões (até $100 \mathrm{hPa}$ ) é imprescindível para diferenciação entre os poros capilares (microporos) e não-capilares (macroporos) (Oliveira, 1968), bem como no estudo da retenção da água no solo.

Os equipamentos empregados na aplicação de tensões utilizam o processo de sucção ou vácuo. A base desses métodos é o estabelecimento de um contato hidráulico entre o solo e um meio poroso, o qual possui poros tão pequenos que o solo permanece em estado de saturação até que uma elevada sucção (ou tensão) seja estabelecida (Townend et al., 2000). A tensão pode ser aplicada por meio de uma coluna de água ou uma bomba reguladora de vácuo, de modo que o solo em contato com o meio poroso perde ou ganha água de acordo com a tensão aplicada, ou seja, se a tensão for maior que o valor inicial da água presente no solo, ocorrerá a perda de água.

O equilíbrio entre a amostra de solo e a tensão aplicada pode ser determinado pelo processo de pesagem, até que a amostra de solo atinja peso constante, ou o fluxo da água cesse ou torne-se mínimo (Klute, 1986; Townend et al., 2000). O tempo de equilíbrio de uma amostra de solo, usualmente, demora em torno de um a sete dias, dependendo da natureza do solo, da altura da amostra e da tensão aplicada (Klute, 1986). Romano et al. (2002) afirmaram que, se dois pesos consecutivos de uma amostra de solo não diferirem mais do que $0,1 \mathrm{~g}$, pode ser assumido o equilíbrio hidráulico.

Um dos equipamentos de sucção mais utilizados é o funil de Büchner, introduzido por Bouyoucos (1929) e adaptado por Haines (1930). Esse equipamento tem como meio poroso uma placa de cerâmica, que, de acordo com a literatura, possui várias formas de instalação (Haines, 1930; Danielson \& Sutherland, 1986; Townend et al., 2000). O funil de Büchner ou funil de Haines, como é atualmente conhecido, tem como principal limitação o uso de apenas uma amostra de solo por vez, necessitando de vários funis para agilizar a determinação da curva de retenção. Tentando amenizar essa limitação, Leamer \& Shaw (1941) e Oliveira (1968) propuseram o uso de uma mesa, com capacidade para várias amostras, em que a tensão fosse aplicada diretamente em um papel do tipo mata-borrão. Esse método tem como desvantagem a necessidade de troca constante das folhas de mataborrão e a dificuldade na aquisição desse material, bem como o fato de ele não suportar a aplicação de tensões relativamente elevadas, próximas às da capacidade de campo.
Stakman et al. (1969) popularizaram o uso da mesa de tensão (sucção) utilizando camadas de areia, em vez da aplicação da tensão em uma placa de cerâmica ou em camadas de papel (Clement, 1966). Nesse método, a tensão é aplicada diretamente em camadas de areia muito finas, ou camadas de areia e caulim, colocadas dentro de um recipiente. No entanto, essa mesa de areia apresentou os seguintes problemas: (1) o meio poroso composto de areia e caulim possuía baixa eficiência na remoção de água das amostras e grande variação na tensão aplicada; (2) o excesso de caulim em relação à quantidade de areia resultava em entrada de ar no meio poroso; e (3) era necessário longo tempo de equilíbrio, devido ao tamanho das amostras e ao baixo contato estabelecido pelo material (Topp \& Zebchuk, 1979).

Devido à grande utilidade das mesas de tensão e à necessidade de conhecer a umidade do solo próximo à capacidade de campo, algumas versões melhoradas desses equipamentos são comercialmente disponíveis em outros países (Romano et al., 2002). A carência de publicações científicas, no Brasil, sobre os procedimentos de montagem e de validação dos resultados obtidos nas mesas de tensão com areia tem restringido o amplo uso desse equipamento. Tendo em vista constantes solicitações de cópias e método de manejo do referido equipamento, o presente trabalho foi organizado com o objetivo de apresentar o procedimento de montagem e utilização de uma mesa de tensão, constituída de camadas de areia de quartzo moído, bem como sua eficiência e exatidão na determinação da retenção de água no solo até 100 hPa.

\section{MATERIAL E MÉTODOS}

\section{Descrição do equipamento}

A mesa de tensão utiliza uma panela de $\mathrm{Al}(0,54 \mathrm{~m}$ de diâmetro e 0,23 $\mathrm{m}$ de altura) como recipiente para a montagem das camadas de areia. A vantagem desse tipo de recipiente é que pode ser adquirido facilmente no comércio, é de baixo custo e de fácil manuseio, além de conter uma tampa própria, o que facilita o fechamento e impede a evaporação. Entretanto, outros recipientes poderão ser utilizados, desde que sejam rígidos, impeçam o vazamento de água e não enferrujem. Recipientes feitos de cerâmica ou plásticos ligeiramente rígidos são utilizados com sucesso (Townend et al., 2000).

A mesa de tensão possui capacidade para 40 amostras de solo, considerando o uso de anéis volumétricos de 5 × $5 \mathrm{~cm}$ (Quadro 1). O sistema de drenagem é estabelecido pela conexão da mesa de tensão a uma coluna de vidro por meio de uma mangueira de silicone. A mangueira funciona como a armação em U utilizada no funil de Haines (1930), 
e a coluna de vidro, como um reservatório, onde o tubo de drenagem (local de saída da água), quando aberto, estabelece a sucção da água num determinado potencial e, quando fechado, funciona como um frasco de mariote, retornando a água para a mesa até que o equilíbrio seja estabelecido. A mesa de areia permite a aplicação de tensões entre 0 e $100 \mathrm{hPa}$,

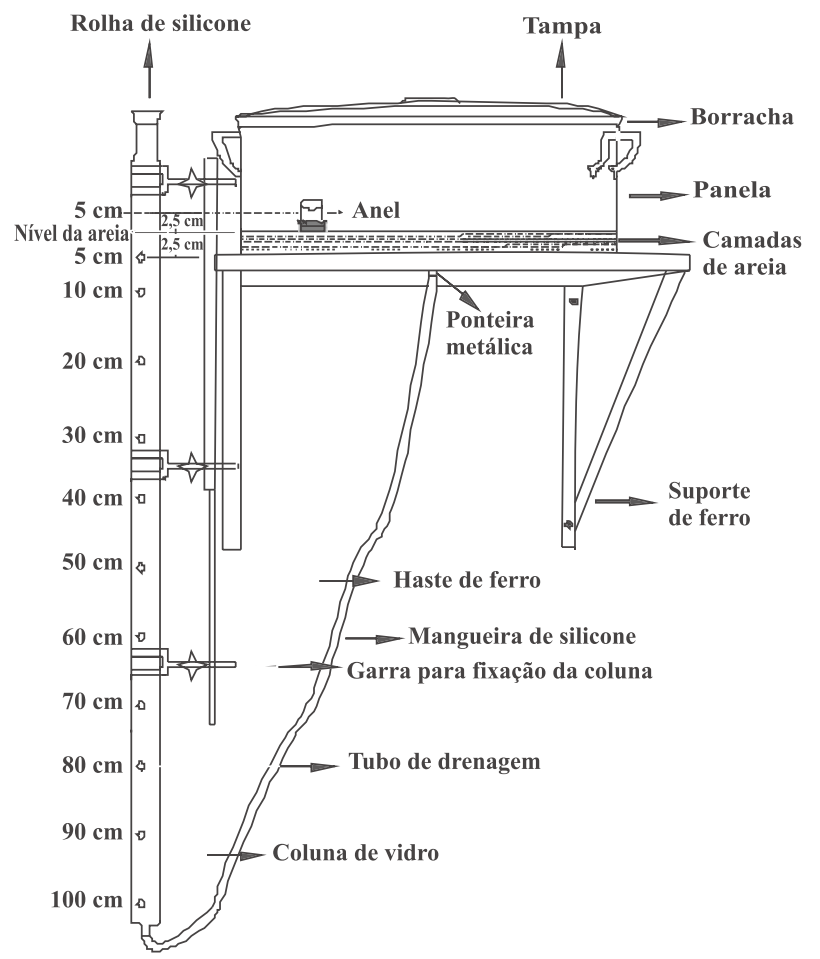

Figura 1. Esquema mostrando os componentes da mesa de tensão de areia. ou seja, desde a completa saturação da amostra até a umidade na capacidade de campo.

Detalhes da armação e montagem da mesa de areia são apresentados nas figuras 1 e 2 , e as especificações dos materiais utilizados na montagem da mesa de areia são amostradas nos quadros 1 e 2 .

\section{Procedimento de montagem}

Para dar início à montagem da mesa de tensão, um orifício pequeno foi feito no centro do recipiente (panela de $\mathrm{Al}$ ), no qual foi soldada uma ponteira metálica, onde se conectou uma mangueira de silicone. A mangueira serviu de canal entre a mesa de areia e a coluna de vidro (Figura 1). Para favorecer a aderência da areia com a superfície da panela, foram

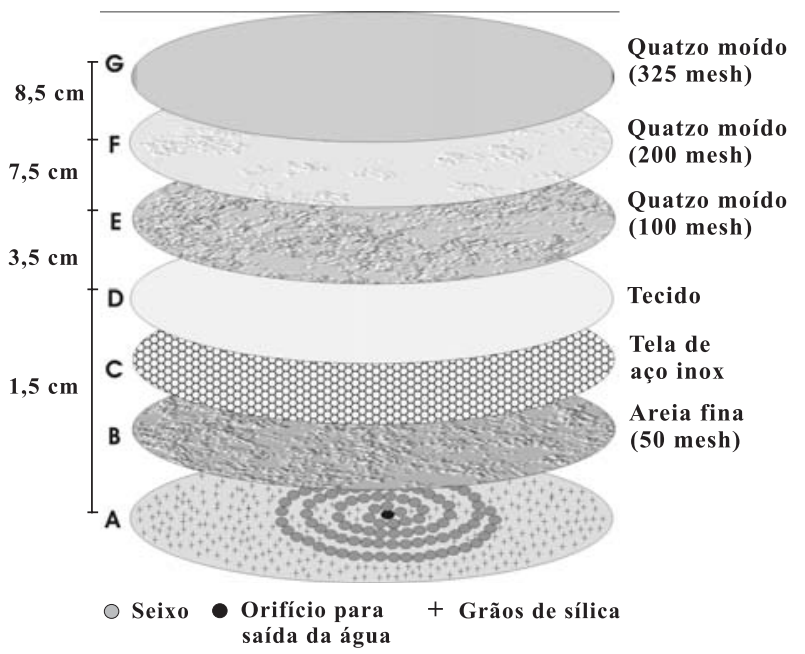

Figura 2. Esquema mostrando a sobreposição das camadas que compõem a mesa de tensão.

Quadro 1. Especificações do material utilizado na montagem da mesa de tensão

\begin{tabular}{|c|c|c|c|}
\hline Equipamento & Material & Dimensões & Fornecedor \\
\hline Panela & Alumínio ou plástico rígido & $0,54 \mathrm{~m} \quad(\mathrm{DI}) ; 0,23 \mathrm{~m} \quad(\mathrm{H})$ & - \\
\hline Ponteira & Metal ou plástico rígido & $28,13 \mathrm{~mm}(\mathrm{DI}) ; 6,27 \mathrm{~mm}(\mathrm{H})$ & - \\
\hline Mangueira & Silicone & $6,31 \mathrm{~mm}(\mathrm{DI})$ & - \\
\hline Coluna & Vidro & $\approx 130 \mathrm{~cm}(\mathrm{H}) ; 40,19 \mathrm{~mm}(\mathrm{DE})$ & Vidropim $^{(1)}$ \\
\hline
\end{tabular}

(1) Rua Oscar Lourenzo Fernandes 299, Bro. Santa Cecília, Piracicaba (SP). DI: diâmetro interno; DE: diâmetro externo; H: altura.

Quadro 2. Descrição do material utilizado nas camadas de areia

\begin{tabular}{|c|c|c|c|}
\hline Camada & Descrição do material & Dimensões & Fornecedor \\
\hline \multirow[t]{2}{*}{$\mathrm{A}$} & Seixos & $\approx 19 \mathrm{~mm} \varnothing$ & \multirow[t]{2}{*}{ Material utilizado em jardim } \\
\hline & Grãos de sílica & Peneira de 4 a $6 \mathrm{~mm}$ & \\
\hline $\mathrm{B}$ & Areia fina & Malha de 50 mesh & \multirow{2}{*}{$\begin{array}{l}\text { Prominérios Comercial Ltda } \\
\text { _ }\end{array}$} \\
\hline $\mathrm{C}$ & Tela de aço inox & Malha de $2 \mathrm{~mm}$ & \\
\hline $\mathrm{D}$ & Tecido & Tipo vual & - \\
\hline $\mathrm{E}$ & Quartzo moído & Malha de 100 mesh & \multirow[t]{3}{*}{ Prominérios Comercial Ltda ${ }^{(1)}$} \\
\hline $\mathrm{F}$ & Quartzo moído & Malha de 200 mesh & \\
\hline $\mathrm{G}$ & Quartzo moído & Malha de 325 mesh & \\
\hline
\end{tabular}

(1) Av. Lasar Segall, 400, Imirim, CEP: 02543-010 São Paulo (SP). 
lixados os primeiros $9 \mathrm{~cm}$ da parte interna, bem como a sua base. Em seguida, foram feitos alguns círculos com cola de silicone $( \pm 3)$ ao redor do orifício de saída de água e, sobre a cola, foram adicionados alguns seixos $(\approx 19,1 \mathrm{~mm}$ de $\varnothing)$, de forma que ficassem bem firmes e não se movimentassem com a passagem da água, impedindo a perda de material. Um seixo maior foi colocado sobre a saída da água e os espaços restantes foram preenchidos com grãos de sílica (4-6 mm de $\varnothing$ ) (camada A - Figura 2). Sobre os grãos de súlica foi adicionada uma camada de areia fina (camada B - Figura 2), que preencheu todos os espaços vazios. Água deaerada foi utilizada para facilitar a acomodação dos grãos de sílica e distribuir uniformemente as camadas de areia, bem como inibir o aparecimento de bolhas.

Para impedir que bolhas de ar se formassem entre as camadas e facilitar a acomodação e o empacotamento das partículas, foi mantida uma lâmina de água constante, com auxílio de uma mangueira, de forma que estas estivessem sempre saturadas. Para manter a condição de saturação, a saída de água da panela foi fechada.

Sobre a camada de areia fina (camada B - Figura 2) foi colocada uma tela de aço inox com malha de $2 \mathrm{~mm}$, distribuída por todo o diâmetro interno da panela (camada C - Figura 2). Os espaços entre as malhas da tela foram preenchidos com a areia fina para evitar a formação de bolhas de ar e, em seguida, a tela foi totalmente coberta com um tecido fino (voal) (camada D - Figura 2), que serviu de barreira à passagem das camadas sobrejacentes. A montagem das camadas foi realizada de modo que na sua finalização elas não ultrapassassem $1,5 \mathrm{~cm}$ de altura (Figura 2). A fixação do tecido sobre a tela de inox foi feita com o auxílio de uma pequena quantidade de areia fina.

Uma camada de pó de quartzo moído (100 mesh) foi alocada sobre o tecido até que sua altura atingisse $3,5 \mathrm{~cm}$ da base da panela (camada E - Figura 2), sempre com o auxílio de água, para acomodar o material. Posteriormente, foi montada uma camada de quartzo de 200 mesh, até a altura de $7,5 \mathrm{~cm}$ (camada F - Figura 2). Em seguida, uma camada de pó de quartzo de 325 mesh (camada G - Figura 2) foi adicionada até que restasse somente $0,5 \mathrm{~cm}$ para finalização da última camada. Os centímetros restantes foram utilizados durante o processo de nivelamento.

\section{Calibração e funcionamento da mesa de tensão}

Uma haste de ferro foi fixada na parede do laboratório, servindo de suporte para a mesa de areia e para a coluna de vidro (Figura 1). A mesa foi instalada em um ambiente refrigerado, para impedir a evaporação e a condensação da água nas paredes do recipiente, o que pode alterar o conteúdo de água das amostras. Ball \& Hunter (1988) sugerem que, durante o uso da mesa de tensão, o ambiente esteja a uma temperatura de $22 \pm 3{ }^{\circ} \mathrm{C}$.
A coluna de vidro foi graduada de 10 em $10 \mathrm{hPa}$ até $100 \mathrm{hPa}$, por meio de tubos de drenagem. Após os tubos estarem bem fechados, a coluna foi preenchida com água deaerada e fixada no suporte de ferro, com auxílio de garras metálicas (Figura 1). A vedação da parte superior da coluna foi feita com uma rolha de borracha (ou silicone), de forma que, após a sua vedação, a água não saísse da coluna, mesmo que a parte inferior estivesse aberta. A grande vantagem dessa coluna é o fato de ela permanecer fixa a um suporte e não ser necessário sua remoção durante a mudança da tensão aplicada.

Após a panela ser colocada no suporte, a mangueira de silicone conectada à mesa e completamente cheia de água foi inserida na coluna de vidro. É importante que haja bastante água acima do nível da areia $( \pm 3 \mathrm{~cm})$, para facilitar o processo de drenagem.

Para nivelar corretamente a mesa, o tubo de $5 \mathrm{~cm}$ do primeiro ponto de drenagem foi fixado a $2,5 \mathrm{~cm}$ abaixo do nível da areia e $5 \mathrm{~cm}$ abaixo da metade do anel cilíndrico (Figura 1). Depois de nivelada, foi aberto o primeiro tubo $(5 \mathrm{~cm})$ para drenagem do excesso de água. Uma das formas utilizadas para conferir o nivelamento da mesa foi a observação do gotejamento: quando a água drenou muito rápido, sem gotejar, foi utilizado o pó de quartzo para completar os $8,5 \mathrm{~cm}$ finais da última camada (camada $\mathrm{G}$ Figura 2), favorecendo assim o gotejamento. Um nível de bolha também foi utilizado para aferir o nivelamento da mesa de areia.

Para evitar a evaporação das amostras na mesa de tensão, foi colocada uma borracha na borda da panela, idêntica àquelas utilizadas para vedação de porta-mala de automóveis, e sob ela foi espalhada vaselina sólida. A mesa foi mantida sempre saturada, mesmo quando não estava sendo utilizada.

O funcionamento da mesa consiste na colocação de amostras de solo saturadas em contato direto com o meio poroso, onde a altura do tubo aberto na coluna será igual à tensão aplicada na amostra de solo. A cada tensão aplicada, um nível de equilíbrio será estabelecido, sendo, em cada ponto, determinada a umidade gravimétrica do solo (Ug) e o potencial mátrico $\left(h_{\mathrm{m}}\right)$. Esses pares de medidas, Ug e $h_{\mathrm{m}}$, são utilizados na curva de retenção da água no solo.

O número de tensões, ou do conjunto de medidas, Ug e $h_{\mathrm{m}}$, a serem utilizadas dependerá do objetivo proposto em cada trabalho, sendo possível a aplicação de 11 tensões na mesa de areia aqui apresentada: 5, 10, 20, 30, 40, 50, 60, 70, 80, 90 e 100 hPa. E importante anotar a localização de cada anel dentro na mesa de tensão; assim, ao retirá-lo para pesagem, ele será recolocado na mesma posição, favorecendo o contato hidráulico.

\section{Validação da mesa de tensão}

Para validação da mesa de tensão foram utilizados dois equipamentos: minitensiômetro e câmara de pressão de Richards. 
Minitensiômetro: foram coletadas 28 amostras indeformadas, em uma transeção de $140 \mathrm{~m}$ no município de Tibagi (PR), utilizando anel volumétrico de $5 \times 5 \mathrm{~cm}$. As amostras apresentaram conteúdo de argila variando de 105 a $316 \mathrm{~g} \mathrm{~kg}^{-1}$, densidade do solo (Ds) entre 1,24 e $1,57 \mathrm{~g} \mathrm{~cm}^{-3}$ e CO com 19,8 a $39,0 \mathrm{~g} \mathrm{~kg}^{-1}$.

As amostras foram saturadas elevando-se gradualmente uma lâmina de água numa bandeja, até atingir cerca de dois terços da altura da amostra, durante $24 \mathrm{~h}$. No entanto, amostras com alta quantidade de argila dispersa em água, ou que esboroam quando imersas em água, devem ser saturadas na própria mesa, visando evitar danos na estrutura e perda de material durante sua transferência. A desvantagem desse último método de umedecimento é que os poros grandes podem não ser preenchidos completamente e a amostra de solo não atingir corretamente o conteúdo de água na saturação. Para evitar que isso ocorra, deve ser adicionada água na mesa até que seja observada a completa saturação das amostras.

Depois de saturadas, as amostras foram colocadas na mesa para aplicação de uma tensão de $100 \mathrm{hPa}$. O equilíbrio foi estabelecido em sete dias, indicado pela ausência de gotas de água e a formação de meniscos nos tubos de drenagem, conforme Klute (1986). Em seguida, as amostras foram pesadas e colocadas em estufa a $105^{\circ} \mathrm{C}$, durante $24 \mathrm{~h}$, para determinação da umidade e da densidade do solo (Ds), de acordo com Gee \& Or (2002a). A distribuição do tamanho de partículas foi determinada pelo método da pipeta (Gee $\&$ Or, 2002b).

A umidade na tensão de $100 \mathrm{hPa}$ foi determinada pela seguinte fórmula:

$$
\mathrm{Ug}_{100 \mathrm{hPa}}=\frac{M s u-M s s}{M s s}
$$

em que $M$ su é a massa de água na tensão de $100 \mathrm{hPa}$ e MSS é a massa de solo seco em estufa. O mesmo procedimento é repetido para determinação da umidade em outras tensões.

Para confirmar a tensão aplicada na mesa de areia, após o equilíbrio e a pesagem, utilizou-se um minitensiômetro (USM measure - modelo T5), acoplado a um datalogger digital. Para isso, o tensiômetro com uma cápsula porosa de $20 \mathrm{~mm}$ de diâmetro foi inserido no meio de cada amostra de solo por um tempo mínimo de 30 s para determinação da tensão.

Câmara de pressão de Richards: foram utilizadas 40 amostras de solo, sendo 20 com textura argilosa (430 $\mathrm{g} \mathrm{kg}^{-1}$ de argila) e 20 com textura franco-argiloarenosa (300 $\mathrm{g} \mathrm{kg}^{-1}$ de argila). Em cada mesa foram colocadas 10 amostras, considerando a classe textural. As amostras foram saturadas, pesadas e submetidas aos seguintes potenciais: 40, 60, 80 e $100 \mathrm{hPa}$ na câmara de pressão de Richards e na mesa de tensão. Para aplicação exata desses potenciais na câmara de pressão, foi utilizado um manômetro digital.

\section{RESULTADOS}

Nas amostras equilibradas na tensão de $100 \mathrm{kPa}$, as leituras do minitensiômetro variaram entre $95 \mathrm{e}$ $109 \mathrm{kPa}$. A diferença entre as leituras feitas no minitensiômetro e a tensão aplicada na mesa de areia $(100 \mathrm{hPa})$ foi testada pela hipótese de nulidade $(\mathrm{H0}=$ $100 \mathrm{kPa}$ ), obtendo-se $t(27)=0,43 ; \mathrm{p}>t=0,6720$. Ou seja, todas as amostras analisadas foram equilibradas no mesmo potencial, independentemente da variação no conteúdo de argila (Figura 3) e no C orgânico do solo (Quadro 3). O desvio-padrão observado nos valores da umidade gravimétrica (Ug) indica que o método da mesa de areia não introduz variações adicionais para obtenção da tensão aplicada (Quadro 3).

$\mathrm{Na}$ figura 4 são apresentados os resultados da umidade gravimétrica obtidos para todas as amostras em conjunto, considerando os dois métodos de aplicação da tensão, a mesa e a câmara de Richards, com coeficiente de correlação igual a 0,9. Para os potenciais entre - $40 \mathrm{hPa}$ e $-100 \mathrm{hPa}$, a variância dos dois métodos se assemelha, e a dispersão dos pontos de umidade gravimétrica se equilibra com relação à freqüência nos dois lados da curva 1:1 (Figura 4). Isso sugere que o método da mesa de tensão com areia, aqui proposto, é eficiente para determinação da umidade e do potencial da água no solo.

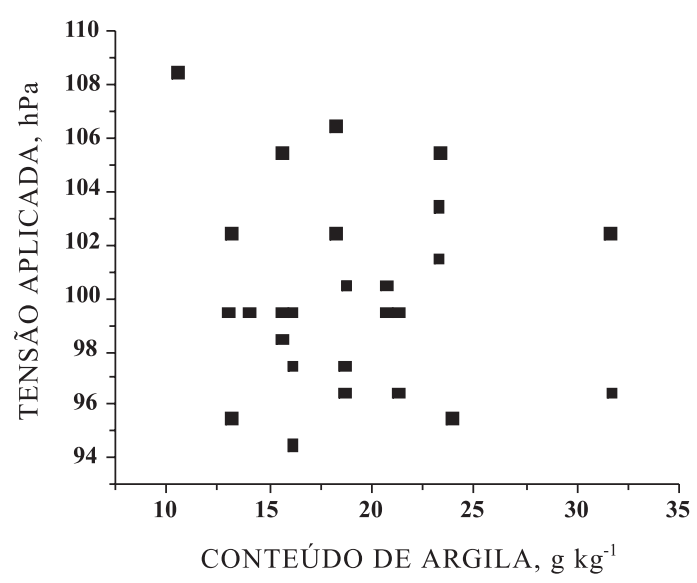

Figura 3. Variação da tensão aplicada pela mesa de tensão em amostras de solo, medida com um minitensiômetro, em função do conteúdo de argila.

Quadro 3. Momentos estatísticos dos resultados obtidos na mesa de areia e com o minitensiômetro

\begin{tabular}{lllllll} 
Variável & No & Média & Mín. & Máx. & Dp & CV \\
\hline & & & & & & $\%$ \\
Ug $\left(\mathrm{g} \mathrm{g}^{-1}\right)$ & 28 & 0,17 & 0,13 & 0,24 & 0,03 & 18,0 \\
$\begin{array}{l}\text { Tensão: } \\
\text { Minitensiômetro }(\mathrm{hPa})\end{array}$ & 28 & 100 & 95 & 109 & 3,53 & 3,5
\end{tabular}

Dp: desvio-padrão, CV: coeficiente de variação (\%). 


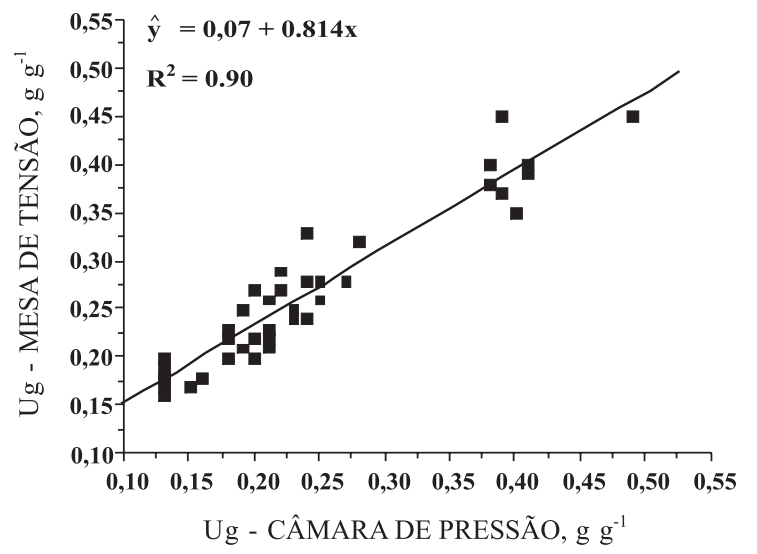

Figura 4. Valores da umidade gravimétrica (Ug) de amostras de solo saturadas e nas tensões de 40, 60, 80 e100 hPa, utilizando os métodos da mesa de tensão com areia e da câmara de pressão de Richards. № $=40$.

\section{LITERATURA CITADA}

BALL, B.C. \& HUNTER, R. The determination of water release characteristics of soil cores at low suctions. Geoderma, 43:195-212, 1988.

BOUYOUCOS, G.J. A new, simple and rapid method for determination the moisture equivalent of soils, and the role of soil colloids on this moisture equivalent. Soil Sci., 27: 233-241, 1929.

CLEMENT, C.R. A simple and reliable tension table. J. Soil Sci., 17:134-135, 1966

DANIELSON, R.E. \& SUTHERLAND, P.L. Porosity. In: KLUTE, A., ed. Methods of soil analysis: Physical and mineralogical methods. 2.ed. Madison, American Society of Agronomy; Soil Science Society of America, 1986. p.443461.
GEE, G.W. \& OR, D. Bulk density and linear extensibility. In: DANE, J.H. \& TOPP, G.C., eds. Methods of soil analysis. Madison, Soil Science Society of America, 2002a. p.201227.

GEE, G.W. \& OR, D. Particle-size analysis. In: DANE, J.H. \& TOPP, G.C., eds. Methods of soil analysis. Madison, Soil Science Society of America, 2002b. p.255-293.

HAINES, W.B. Studies in the physical properties of soil. J. Agric. Sci., 20:97-116, 1930.

KLUTE, A. Water retention: Laboratory methods. In: KLUTE, A. ed. Methods of soil analysis: Physical and mineralogical methods. 2.ed. Madison, American Society of Agronomy; Soil Science Society of America, 1986. p.635660.

LEAMER, R.W. \& SHAW, B. A simple apparatus for measuring noncapillary porosity an extensive scale. J. Am. Soc. Agron., 33:1003-1008, 1941.

OLIVEIRA, L.B. Determinação da macro e microporosidade pela "mesa de tensão" em amostras de solo com estrutura indeformada. Pesq. Agropec. Bras., 3:197-200, 1968.

ROMANO, N.; HOPMANS, J.W. \& DANE, J.H. Suction table. In: DANE, J.H. \& TOPP, G.C., eds. Methods of soil analysis. Madison, Soil Science Society of America, 2002. p.692-698.

STAKMAN, W.P.; VALK, G.A. \& van der HARST, G.G. Determination of moisture retention curves. I. Sandbox apparatus, range $\mathrm{pF} 0$ and 2.7 3.ed. Wageningen, Institute for Land and Water Management Research, 1969.

TOPP, G.C. \& ZEBCHUK, W. The determination of soil-water desorption curves for soil cores. Canadian J. Soil Sci., 59:19-26, 1979.

TOWNEND, J.; REEVE, M.J. \& CARTER, A. Water release characteristic In: SMITH, K.A., ed. Soil and environmental analysis: Physical methods. 2.ed. New York, Marcel Dekker Incorporated, 2000. p.95-140. 